\title{
Does teaching by cases mislead us about morality?
}

\author{
Christopher Miles Coope University of Leeds
}

\begin{abstract}
Those who teach or are taught medical ethics with a heavy reliance on case studies should be warned first of all that the practice tends to exaggerate the degree to which morality is controversial. Secondly, they ought to realise that it is often quite unclear what problems count as moral problems. Thirdly, they will need to bear in mind that there may be - and presumably are - limits to what we may regard as open to discussion. It would be quite superficial to assume that ethics teachers, going along with what is generally accepted by their colleagues in this matter, would never tempt students to disregard these limits.
\end{abstract}

Medical ethics will often be taught by a consideration of case-studies. We are all familiar with what goes on. The student will be taken on a ward-round of curious examples, which at least pretend to be drawn from actual cases, in order as it were to give him or her experience on the job: the job of moral judgment. He will not come unprepared to the task, for there will have been some introductory material offering various 'moral theories' (bundled up like tools in a tool-box), but he will - I suspect - not come very well prepared either (1). I have certain disquiets about this way of proceeding which I want to share with you.

Nothing that I say is meant to suggest that the employment of case-studies is out of place in teaching ethics. Even Jesus taught in parables (2). It is perhaps better to teach in this way than depend upon the uncertainties, absurdities even, of what is called moral theory. And I shall myself make a certain use of the case-study method in putting my argument.

First of all, we should ask ourselves whether the continued use of controversial examples serves to exaggerate the extent to which morality, as distinct from moral theory, is controversial. By way of balance, it would be useful to take examples of what

\section{Key words}

Case studies; teaching ethics; consequentialism; moral theory. we suppose (some philosophers apart) to be quite uncontroversial wrong-doings: killing a patient in order to provide useful organs for other patients, kidnapping a more or less rational adult patient off the street and administering much needed therapy against his will, telling straightforward lies to the local authority in order to improve one's services - that sort of thing - and then raise the question why these actions are wrong. It is very easy to give unsatisfactory answers (3). In this way, as indeed in regard to so many of our everyday 'non-moral' beliefs, we can come to understand better what we already know. One might followo Richard Hare's terminology here, and talk of 'two levels' (4): a level at which we know (quite often) whato we must or may do, and a level at which we seek to understand the musts and mays in question. (Naturally, a claim to know that a doctor should not be killing his patients to provide organs, etc, leaves us open to the familiar charge of 'simplistic common sense intuitionism'; but if we do not pretend to support our convictions by appeal to uncanny Intuitive Powers, powers of Moral Cognition, possessed either by ourselves or by some moral majority, the force of such a charge is none too clear.)

This effort at understanding should be put alongside our study of cases. For if our deeper understanding of the moral truisms we fitfully live by is faulty or inadequate, it is hard to see how a consideration of difficult cases will help us. This better understanding might even be a precondition for dealing with the cases. (Insofar that is to say as they can be dealt with at all, for we should always remember that the concepts we employ, such as 'harm', 'intention', 'human good', 'injustice', 'murder', 'consequence', etc, all have vague boundaries, and hence might give rise to many problem cases that have no solutions.) Of course, if a case is not difficult the teacher might use it simply as a test. For example, the following case study, which is possibly corrupting, could be offered to a child:

Case study one: The needed bun: You are hungry. In the shop window there is a lovely cream bun costing 10 pence. Your classmate James has 10 pence in his 
coat pocket. His coat is hanging in the corridor. No one is looking. What do you do now?

But if the person setting the problem does not know the answer, or even how to search for it, it becomes a little unclear what the case study, as teaching material, is intended to achieve.

So there is this reason for disquiet. However, there are two further reasons which require more extended discussion. Basically, I want to suggest that the case-study method may encourage us to ask questions that should not be asked. I think I can see this encouragement in the teaching at which I have been present, and I don't suppose that my experience has been in the least unusual. What I offer here is merely a caution. I do not propose to discuss whether two per cent or 92 per cent of our students are misled in the ways I suggest. One can usefully warn that stones are slippery without knowing how many people have actually slipped on them.

I have suggested that our practice of appealing to case studies may invite us to ask questions that we should not be asking. There are two quite different dangers here. Some questions do not arise. Other questions ought not to arise. I shall deal with each kind of danger in turn.

My first worry can be brought out with the aid of the following case study, based on a real life example. (I have altered the details to preserve anonymity.)

Case study two: Slippers in the kitchen: You are sitting at home by the kitchen table. You have your slippers on. There is a newspaper at your elbow. You have not written to any of your aunts that day. It is raining - and Tuesday. What ought you to do?

Of course one would be rather surprised to be asked to consider such a case. But can we be so very sure that cases of this undiscussable kind are not in fact put before our students? The question: 'What ought you to do?' is clearly foolish in this context, as everyone will see at once. Why? People will agree that the question is foolish, but they may not agree on their reason. Is the question foolish simply because we have not been given enough detail?

\section{Straightforward utilitarianism}

Let us first make a passing nod in the direction of straightforward utilitarianism. Any straightforward utilitarian, as I use the phrase, will think that one has a duty to maximise something, such as happiness, pleasure, preference satisfaction, respect for rights, average utility, or whatever (maybe a combination of various ingredients: a little happiness here, topped up with rights-respecting there, and so on). Such a person will not of course be able to answer our casestudy question from his simple utilitarian perspective. He would need much more information! In fact one would not expect him to take much interest in case studies, for would he not always want to know more? And even those more moderate individuals who think we ought always to be producing a 'satisfactory amount' of some good would be in trouble. But I do not want to dwell on these difficulties, for it is hard to believe that there are any real utilitarians of any of these simple kinds, as opposed to the nominal utilitarians one meets in the classroom who are no doubt as plentiful as nominal members of the Church of England, and of course blackberries (5). However, I think that our case-study question would also be found unsatisfactory by ordinary reflective people quite unacquainted with utilitarianism or with any other -ism for that matter. Why?

\section{Perpetually directive}

Doesn't the case-study method here presuppose or suggest that morality is perpetually directive - that however hard it might be for us to find, there is always such a thing as The Moral Thing To Do? Or perhaps a disjunction of several trivially distinct Moral Things (like setting off with this foot or with that)? Or, if it is supposed that there are 'moral dilemmas', where anything one might do would have what would be called a 'moral cost', doesn't the case-study method rather take for granted that there would at least be The Right Wrong Thing To Do? True enough, one might need more information - as indeed the utilitarian mentioned in our last paragraph would have insisted, there being hardly any limit to the information he would need. But would more information always make a difference? Suppose, for example, we were to add to our case study the item that someone on the other side of the town would be cheered up by a visit? Would the moral must then come into the picture? I think not.

One way, an exceedingly common way, of thinking of morality is to regard it as a set of boundary injunctions. We would be thinking here of the morality which divides actions into the 'all right' and the wrong, the permissible and the forbidden, or of the requirements of justice (where this is not thought of as an exclusively distributive matter, but has to do with what is owed to others). It is of course absurd to object to a morality of boundaries, of rules, as if it were old-fashioned, a mere hangover from the Jewish roots of our civilisation, something only suitable for children. The morality of boundaries cannot, to be sure, be the whole story; but it is more of the story than is commonly supposed. According to this account, there would be such a thing as moral freedom, within these limits - so it is a view of morality that one might expect to appeal to liberals. Contrast the popular academic idea that one has a general obligation to satisfy preferences. Here one would be entirely hemmed in by obligations. If one were sitting in the kitchen in one's slippers and would like a cup of coffee, then prima facie one 
would have an obligation to put the kettle on. The difficulty would be to move from one's prima facie obligations, so easy in many cases to discern, to The Right Thing To Do all things considered.

Morality certainly does set boundaries: one must not kill, steal, lie, etc. (Of course, I state these injunctions in a simple way, as a kind of shorthand, suitable for the most elementary instruction; everyone recognises that the moral teachings in question might be quite complex.) Many of these injunctions are naturally thought of as negative, and that is why the word boundary is perhaps appropriate. Given these boundaries, we might take the question, 'What ought you to do?', to be asking 'What ought you NOT to do? Presumably the question in Case Study One above was asked in this spirit. Not all the injunctions, however, are negative. Thus one would have actively to care for an infant just discovered on one's lonely doorstep on a winter's night. This would be so, even if the infant had been left by a malicious individual wishing to impose a duty of care. And here one would cross a forbidden boundary by 'doing nothing', by shrugging one's shoulders with the thought, it's no business of mine.

Now it would be indeed hard to think of a situation in which one was unable, if so minded, to cross at least one of these boundaries. For we live, for example, under the boundary-injunction not to indulge in certain uncharitable thoughts. And this is a boundary that is always within reach. So of course, if asked What is The Moral Thing To Do, while sitting by the fireside with one's slippers on, etc, one can always say: 'Don't Cross The Boundaries!' (In this sense of course, morality will be perpetually directive.) But this is not answering the question in the spirit in which it is asked, and it is the question asked in this spirit that needs to be rejected. There is often nothing that could be called the moral thing to do, just as there would be nothing that could be called the amusing or the surprising or the polite thing to do. Imagine yourself talking to a friend in a pub. Now, what is the action that politeness demands? The question might well have no application. Politeness, at best, would simply rule out certain things. (I say 'at best' because someone might suppose that among close friends, at ease with one another, there is no such thing as politeness or impoliteness.)

\section{Incompatible aims}

In the same way as there is often no such thing as the right thing to do, there will often be no such thing, where people have incompatible aims, as the solution which justice demands. One is perhaps inclined to suppose that any such difference in what is wanted could be put to an arbitrator, an arbitrator who would not merely be supposed to patch up a compromise that might be acceptable, with luck, to the parties, but who would consult what justice requires, the idea being that this outcome could, given sufficient knowledge, be worked out, or at least settled by some procedure known to be called for, such as the tossing of a coin. But what makes us suppose that justice has this comprehensive scope? Justice might, in many cases, simply rule out certain ways of settling things, such as killing and lying.

Now I said that there is more to morality than keeping the right side of the boundaries. There are virtues other than justice. But perhaps these can only be exercised in appropriate circumstances. One cannot be patient if one is not being kept waiting. One cannot exercise courage if there is nothing fearful that needs to be faced. But is this true of all the virtues? Is there not always the possibility of a kindly action? These tend, we shall suppose, (with Mill let us say) to be among those admirable actions that are not obligatory. Now consider one of these actions. It might be writing to an aunt. Would it be true that one ought to do just that? It is easy to see that the answer is no, not only because one wrote just yesterday, but because there might be other equally admirable but incompatible actions, and one might choose to do one of those instead. It would hardly be sensible to attempt to write out a long disjunction of admirable possibilities. But can we sayb that one ought to do at least one of these actions? (or, supposing that somehow there is only one would it follow that one ought to do $i t$ ?) The trouble here is to understand this ought. We would not mean that the action is obligatory - we ruled this out when we set up the example. Nor do we mean that the action is advisable in some way. The question, 'What ought I to do?', seems to lack sense.

\section{Sensitivity}

It can be difficult for us to appreciate this point, for we are all so afraid of being accused of insensitivity Like the princess, we want to be able to feel the pea of duty through all those mattresses. If we can't, we invent. Nothing easier. What should one do in that kitchen? One must take the tea to the neighbours, post the slippers to Oxfam, and jolly well settle down to those letters, that's what! Of course, one is not really expected to do anything about it. Sensitivity, here, is all.

Now it might be thought that no one teaching moral philosophy by the use of case studies could seriously offer examples of the slippers in the kitchen variety. But I suspect, by listening in to such instruction, that this can happen. Of course, the unsatisfactoriness is concealed. Here are a couple of examples more or less copied out of Ethics and the Health Services Manager (6).

Case study three: The wrong dose: A staff nurse has given a baby double the normal dose of a drug. The baby had a slight reaction but has now recovered. 
The clinical nurse manager feels that the nurse should be suspended from duty and reported to the United Kingdom Central Council for Nursing, Midwifery and Health Visiting (UKCC).

As the unit general manager, what advice would you give?

Case study four: Incident in the outpatients department: A sister in the outpatients department reports that a patient asked to speak to her confidentially yesterday about an incident the patient says happened to him last time he visited outpatients. He was seen at the end of the session, which overran. The consultant had assured the nurse on the clinic that this was a simple follow-up and added that she was happy to see the patient on her own. The patient now alleges, some weeks later, that the consultant sexually assaulted him. He does not wish to make trouble, however, and does not want the matter to go further; he just thought the sister should know. The consultant is very senior and highly respected, and the sister has worked with her for years.

Sister tells you this: as unit general manager what do you do now?

It will be noted that in both these cases a definite answer is sought: what to do. It is not simply a matter of what is ruled out. I am not saying that these cases are obviously parallel to slippers in the kitchen - only that they might seem on reflection to be so, and that the possibility should be considered. To be sure, a health services manager might have to deal with eventualities like these, and it might very well be useful in the training of managers to consider a range of case studies of this kind. Similarly, politicians might have to have training in how to deal with awkward questions asked on doorsteps while canvassing, or addressed to them by TV interviewers: a certain tact would clearly be needed. But what makes us suppose that there is something called morality that can provide solutions, or sort things out, as distinct from laying down those boundaries? We might answer that morality encourages us, if that's the word, to be fairly considerate, where this is not thought of as a strict matter of duty. And of course a manager is morally obliged to be reasonably attentive to the duties that he has assumed and for which he is paid. It is this background of obligation bound up with the manager's role that makes us suppose that these case studies are radically different from slippers in the kitchen. If cases like these arise, he should take thought and not simply reach for his golf clubs. He is morally obliged to take stock; it does not, however, follow that the problem itself is usefully thought of as a moral one, or that professional ethicists ought to be called in to give advice and to help to detect The Right Things To Do. Difficult choices, where the outcome might seriously affect other people, are not always thought of as moral problems. If a man cannot decide whether to marry Betty or Hettie the last thing he might need is a marital moralist.

So the first consideration when presented with a case study is this: one should ask whether it presents a moral issue at all. It is important to ask this question, even if we cannot always expect the answer to be very clear-cut, as morality must be a pretty vague concept. If we do not attend to this matter we shall find ourselves involved in very tedious discussions. People will be put off medical ethics altogether, save those with an abnormal appetite for uplift. What practical problems count as moral problems - or perhaps better, as issues of justice, or of obligation is a question we need to consider. We live in an era of rising expectations. We expect more and more from morality, and the 'ethicists' who are supposed to know about it. We shall find ourselves invited to discuss Investment Ethics, Culinary Ethics, Leisure Ethics, Chiropody Ethics, Ballroom Dancing Ethics, etc, all with their attendant case studies. There will soon be journals devoted to such topics. All this to the delight of the modern commercial university which cannot see the good for the fees (7).

\section{Second caution}

I turn now to the second caution I wish to make in regard to the case-study method of moral education. My argument so far has amounted to a complain that morality was being taken too seriously; for the idea that there is always something that is demanded of one is surely inspired by over-earnestness. I now want to suggest that in some of our discussions of case studies, morality is not being taken seriously enough. It is perhaps the very extravagance of the morality of perpetual injunction that makes us insensitive to the injunctions that really matter. Once again, I shall make up an example, this time somewhat more elaborate, to bring out the point. In its form it closely resembles case-study questions that I have actually heard discussed, and I also suspect that in its matter it is not a wholly unreasonable parody.

You are to imagine that you are a student at a well-known Central European university in the nineteen-thirties. Your amiable and impressive teacher of philosophy has conscientiously prepared some materials for you. They comprise the usual tour through moral theories, and some case studies, among which you will find the following.

Case-study five: Responsible treatment of the insane: As the head of a psychiatric hospital, you have to decide what is to happen to three of your patients, Herr X, Herr Y, and Frau Z. All are due for termination.

The facts. There are three methods of termination available. The first is painless, but causes convulsions, and this is very distressing for the nursing staff. The second is also painless, and death is peaceful. But the body is rendered useless for 
research purposes. The third method is really quite uncomfortable for the patient, but fortunately does not have to take place when there are nurses present. This method allows valuable experimental work to be undertaken, both before and after death, work that is expected to be of considerable benefit to other patients. Note that the first method is twice as expensive to use as either of the other two. Herr X has expressed a strong preference to be terminated by the second method. When the matter is put to Frau $\mathrm{Z}$ she just giggles. (We cannot get through to Herr $Y$ at all.)

Questions: 1. Which method should you choose?; 2. Would it be wrong to discriminate between these patients?; 3 . Would it make any difference if a large number of patients were to be terminated, and resources were scarce?

Break up into groups of four. You have ten minutes in which to come up with an answer.

Once again we would be rather surprised to be offered this case to consider. (Perhaps we are confident that teaching materials of this kind will never be distributed in our classes. I think, for reasons I shall explain, that this confidence is misplaced. I invented this example before having read Michael Burleigh's instructive Death and Deliverance, 'Euthanasia' in Germany 1900-1945 (8). (We should remember that the doctors in Germany were so often quite ordinary civilised people, living by the standards of their time.) If we were offered such a case to consider, we would, I assume, simply tear up the paper and walk out - if that is to say we had the proper courage: after all, we might be embarrassed about appearing to make a fuss, or appearing 'extreme'. We would tear up the paper in contempt because we would suppose that certain possibilities - one ought rather to call them 'temptations' - were not to be weighed and considered.

But doesn't the case-study method rather presuppose that any course of action is at least open to discussion, if only to be rejected? True enough, a devotee of the case-study method, tolerantly and rationally willing to weigh any issue put in front of him, might himself find fault with Responsible treatment of the insane - on the ground that the questions asked were too restricted. He might say that the first question should have read: 'Which method, if any, should you choose?' But this I suggest is not enough. It is surely part of the virtue of justice that certain possibilities should be off the agenda. People sometimes reject a proposal by saying 'I won't hear of it!' This riposte is often unthinkingly made or light-hearted, but used in earnest, it captures very well what justice sometimes requires of us. We might not all agree exactly when we are 'not to hear' of a certain possibility, and there will be borderline cases where we might anxiously suspect that we ought not to be considering what is on offer, but I dare say we would all confidently include Responsible treatment of the insane.
Note that I am not saying that we should refuse to discuss this sort of case in any way at all. I am in fact discussing it right now. And of course there is a need to discuss why it is wrong to terminate our psychiatric patients. As I said at the beginning, it is important to seek to understand better what we know. Tearing up the paper is not an invitation to stop thinking. But we should not be prepared seriously to consider certain possibilities put to us, and we should not by our participation in such discussions give the impression that we go along with the serious consideration of such possibilities. Such a refusal need not of course be made in a spirit of self-righteousness. For that would indicate a pride that none of us can afford.

Nothing depends here on my particular example. It would be beside the point to say for example that the author of this paper simply has a hang-up about the killing of psychiatric patients, that he dislikes this sort of thing. If there are some kinds of action, perhaps not including the one I suggested, which should not be put before us as options, then our students should be made aware of the fact. They should be aware of their right, indeed their duty, to object to the proceedings and to refuse to participate. To consider whether to X, even in hypothetical circumstances, is after all an action. As an action it if open to moral appraisal; and it might turn out to be bad. A student, unimpressed with the fact that case study had the official blessing of the course instructor, and who was prepared to stand out from the crowd and say 'This is just not something I am willing to discuss, and I suggest you do not discuss it either' should, I think, earn our respect, even if in the particular case he seemed to us to have shown bad judgment. In my experience, students seem quite unmindful that such an issue might arise.

\section{Unreasonableness}

We will perhaps be asked whether someone who teaches or praises this kind of intolerance might not be inviting unreasonableness and ill-will. Well, intolerance certainly has its dangers. But so too does 'a little learning' - though we all have to start by learning a little. (As for much learning it makes a man mad, or so they say.) What kind of moral education is safe? Is it safe for example to teach a critical attitude? Teach someone to be critical and goodness knows what he might do, to his detriment and to ours. Is it safe to teach kindness? Teach a man to be kind and he might think it necessary to be cruel. Sometimes one simply has to live with dangers, as when one drives a car or walks across the road.

If asked why it is necessary to take this line - and there must be some reason - we would perhaps say something like this: that it is important not only to avoid certain actions, but also to avoid certain invitations to action. Someone who works in a bank should not allow himself to dream of what he might 
do with the money. He should not dwell on the what-ifs. 'What if I were in desperate need ...' 'What if my aunt was in desperate need ...?' 'What if it were someone else's aunt ...?' 'What if there were a hundred needy aunts, and the bank had treated me rather badly ... ?' I do not mean to suggest, nor do I believe, that property rights are sacred in the face of need. But a bank employee is in a position of trust, unlike a hungry man walking beside a field of turnips. Doctors who are in charge of the weak and vulnerable have a special duty not to so much as dream of harming them, even in the interests of 'good causes'. Nor should they get themselves used to the idea of harming them by considering invitations to harm incorporated in case studies. Nor, where trust is so important and yet so fragile, should they become involved in earnest discussions about whether a lie might not be for the best in a certain situation - a situation devised especially to make a lie a tempting option. (We might make the same remarks about the police. We ought not to encourage the trainee policemen in our charge to consider case studies in which they are offered the option of ill-treating members of the public, with due expressions of regret, in order to extract important confessions.) If one wanted to corrupt people one might try getting them to agree to do certain beastly things in hypothetical cases. I have no empirical data on the effectiveness of this technique, but it would seem suitable to the job in hand. A gradual approach would clearly be desirable. One would begin by inducing them to accept such things as a live option, as a choice they could respect, even if it would not be their own.

In saying that doctors (and the police) should not be taught in a way which presupposes that certain kinds of wickedness - assisting with torture, let us say - are to be regarded as open to choice, it might be thought that I was wishing to make an exception for philosophers. Philosophers are not often called on to assist with torture - that is a medical, or a military, hazard. But I do not think that we philosophers can safely exempt ourselves. We have our own vulnerability. Those who want to torture might well look to the writings of philosophers, particularly those in applied ethics, for comfort and reassurance. In any case, no one, philosopher or not, can know when he might be tempted into grave wickedness, even torture. So there are kinds of action that human beings quite generally, including philosophers, are not to contemplate.

What I have been saying here is not, I believe, particularly new. It is very much in the spirit of Elizabeth Anscombe's celebrated article 'Modern moral philosophy' (9). And Richard Hare has emphasised that there are certain things that a good man will simply not think of doing (10). Such agreement between philosophers who might be thought to have rather little in common is quite impressive. The point, however, is something that seems rarely to be taken account of: I have never heard it raised in practice when case studies are being thought up or presented (11).

I said just now that I was not at all confident that disgusting case-study material would never be circulated to medical students. I am here moved by four considerations: firstly, that case-study material is thought to be safe: after all, no real decisions are being taken (though efforts are made to make the case studies as realistic as possible, and they are presented to those who are shortly going to face these problems and temptations in real life); secondly, that we are sometime encouraged, in medical ethics circles, to think adventurously, and this sounds just fine until one thinks what it might mean; thirdly, that there seems to be an assumption current that if what one is being asked to contemplate can be described as in some way humane, as relieving distress, or as respecting something called autonomy, it cannot be disgusting; and fourthly, I rely on actual experience. I have actually seen a small sample of what is passed around. In general, I think we need to be vigilant, to be more prepared to question the idea that certain matters can be regarded as open for our consideration. We should certainly not take for granted that proposed discussions are all right simply because they are offered to us by decent-seeming people (who are kind to animals), in a safe British university, with coffee and biscuits provided (12).

Questions will still arise about what is plainly disgusting: for, as we saw at the beginning, we are often better able to grasp that a certain action or kind of action is bad than to explain why this is so. If this still does not seem obvious it might help to reflect how children can readily understand that stealing, let us say, is bad without being able to offer much insight in the matter (13). We should not allow ourselves to conclude that the manifest uncertainty we philosophers have about the deeper theory renders our elementary moral understanding about murder, lying, torturing, etc, entirely questionable, so that 'civilised' toleration is here the order of the day. The case-study method, in my experience, seems to work on the assumption that nothing is excluded $a b$ initio, and that we cannot be soiled by our open-mindedness. It is this assumption that we must be prepared to question.

Christopher Miles Coope, BA, BPhil, is Lecturer in Philosophy in the Department of Philosophy at Leeds University.

\section{References and notes}

(1) I have since found that in these days of economic stringency even this preliminary preparation is sometimes left out. I do not know whether the students lose by this: there are plainly some swings and roundabouts to consider, and the net result might be positive. 
(2) But perhaps to make things difficult. Jesus, in some rather uncomfortable remarks, says that he teaches with the aid of stories so that those who do not have access to his more direct teachings will fail to understand what he is on about. See: Mark, 4.11-12.

(3) Thus we know, without having to subject our view to critical scrutiny, that rape is wrong. But do we know in the same way that rape is wrong just because it is horrifying to the one who is raped? After all, we are so often permitted under justice to act in ways to which others take strong exception. Or is it wrong because it fails to respect something we call autonomy? That might sound satisfactory, seeing that it traces the matter back to someone's favourite list of 'principles'. But is it? And why the fuss about these 'principles' anyhow? An enquiry of this kind can be quite fruitful if we are persistent with it.

(4) Hare R M. Essays in ethical theory. Oxford: Oxford University Press, 1989.

(5) I can see that this remark might be thought unduly frivolous. What about John Stuart Mill and his many followers? But Mill was not a utilitarian in the sense explained: his account of moral obligation, in Utilitarianism, chapter five, nowhere suggests that we have a duty to maximise anything or to produce 'enough' good things. He insists, indeed, and it is not one of his better thoughts, that it is reprehensible to give people more happiness than they can be said to deserve. In fact it is hard to see how his account can be called utilitarian at all. It doubtless sets out to be utilitarian, but ends up, driven by good sense, as something else. One is not sensibly thought of as a practising utilitarian simply because one sometimes offers or accepts what are misleadingly called 'utilitarian reasons', that is to say reasons which appeal to consequences, such as 'it would cheer her up' or 'it would burn the house down'. Nor is one to be held to be a utilitarian merely because one merely thinks that within the bounds of tact, good sense and the moral law, one ought somehow to 'do good'; or if one supposes as is natural that moral injunctions must have a point, and that this point has to do with what is necessary with respect to some good that needs to be secured. (I note that the author of the introductory article on utilitarianism in the Toronto edition of Mill, vol X, by D P Dryer, published by the University of Toronto Press in 1969, begins: 'The majority of serious students of ethics today are utilitarians ...' I clearly do not meet many serious students.)

(6) Wall, A. Ethics and the health service manager. London: King Edward's Hospital Fund for London, 1989.

(7) For an example of these rising expectations in the medical context one could hardly do better than turn to Ian Kennedy's 1980 Reith Lectures. 'The majority of decisions taken by doctors', said Professor Kennedy, 'are not technical. They are, instead, moral and ethical'. (The unmasking of medicine [revised ed]. London: Paladin, 1983: 83. On page 84 this sort of thing is said to be 'a commonplace'). This, the doctrine of pan-moralism as we might call it, is of course excellent news for us in the medical morals and ethics industry. Or it would be, if it were credible.
However, Professor Kennedy immediately goes on to undermine what he has just said. For he adds, most revealingly: 'They are decisions about what ought to be done in the light of certain values'. At that rate, all decisions what to do, even the medically technical ones, to say nothing of those investment, culinary, chiropody, and ballroom dancing decisions alluded to above, are moral decisions. For one decides to act in the light of ends in view, and anything wanted is wanted under the aspect of some good.

(8) Burleigh M. Death and deliverance, 'euthanasia' in Germany, 1900-1945. Cambridge: Cambridge University Press, 1994.

(9) Anscombe G E M. Modern moral philosophy. Philosophy 1958; 33: 1-19.

(10) See reference (4): 64.

(11) We can roughly distinguish between two kinds of difficult case. One is difficult because it is hard to know what morality requires (supposing it to require something). This kind of case will often involve borderlines. We may not be sure whether the killing of an embryo is the killing of a human being, and if it is not, whether there would then be no problem. Or we may not be sure whether something intended to deceive is a lie. But there is another kind of case where the difficulty is one of performance. Sometimes we have to live by a rule, perhaps an inflexible rule, and here we can know in advance that there will occasionally be a cost, and this might be a cost that something good about us, sympathy perhaps, makes it hard to bear. Ao diet of hard cases of the latter kind could well be corrupting. One will call them 'moral dilemmas' ando agonise whether one somehow ought to do the most despicable things.

(12) This brief, somewhat truistic, remark has been found 'extremely irritating' by one of my readers. But it is surely superficial to think - and I hate to labour the point - that the friendly and tolerant atmosphere of a modern university, at least in matters not involving the political correctness of the day, insulates us from corruption.

(13) While there is so much that is good in Anne Maclean's striking book, The elimination of morality, (London: Routledge, 1993), she unfortunately retreats into the mysteries of the unsayable over this search for the 'why'. Mrs Maclean is surely right to argue that an account of 'the value of life' that is at all plausible is simply going to be a reflection, a somewhat misleading reflection, of our beliefs about murder and the duty to rescue, and as such is hardly going to be explanatory. But she then appears to rule out the possibility of further insight. Thus after remarking, perhaps rather optimistically: 'We do not contemplate acting in certain ways; it does not occur to us to do certain things to people' she adds with a flourish, 'And the question of whether or not we are justified in this does not arise' (page 135, italics in text). A distinction is required here between epistemic and explanatory justification. Epistemically, justification might be unnecessary, or indeed impossible. But that does not mean that there is no more to understand. At this point we should side with Richard Hare (4). (I refer to his aim, not of course to his execution of it.) 